\title{
1. Theoretical foundations of the sustainable city-region
}

This investigation of the substance and trajectory of China's campaign to create an ecological civilization and to populate its cities with sustainable and low-carbon technologies and processes is founded upon a theory or strategy of sustainable city-regions. Its origins go back to two founding documents of the University of Kentucky Center for Sustainable Cities (CSC) co-directed by the authors. The first, "The Sustainable Cities Manifesto" (Yanarella and Levine 1992b), was intended to follow the tradition of architectural and urban architectural manifestoes written in the preceding two centuries that took the form of a public declaration of the motivations, guiding assumptions, first principles, and ambitious objectives of an emerging school of thought heralding a new way of organizing and reconstructing social life and/or the built environment (Conrads and Bullock 1975). The second, "Does Sustainable Development Lead to Sustainability?" (Yanarella and Levine 1992a), endeavored to challenge the dominant understanding of sustainable development expressed and institutionalized by the Brundtland Commission report that, in our considered view, was quickly undercutting the radical thrust of strong sustainability.

Despite - or perhaps because of - a rather feeble response to these journal articles from the growing sustainability communities, we continued our theoretical research, urban-architectural design work, and case study analyses, compiling these writings into a book titled The City as Fulcrum of Global Sustainability (Yanarella and Levine 2011). Driven by our frustration and dissatisfaction with the mainstream direction of sustainability research, we also issued a series of caveats to the academic and policy making communities not to pick the low-hanging fruit (Yanarella and Levine 2008); resist the temptations of corporate greenwashing and becoming satisfied with greening techniques as substitutes for strong sustainability (Yanarella, Levine, and Lancaster 2016); and avoid succumbing to the embrace of resilience as the end-goal over an increasingly confused and uncertain understanding of and commitment to strong and vibrant sustainability (Yanarella and Levine 2011).

This chapter is a recapitulation of the general framework of our strong sustainability theory of sustainable city-regions, including the key components incorporated into it, and major arguments supporting that strategy. Along the 
way, it introduces the idea of the Sustainable Area Budget, the Sustainability City Game, the Partnerland concept, Multiple Scenario-Building, and the Sustainability Engine ${ }^{\mathrm{TM}}$. Then, given our theory's commitment to carrying capacity as a critical foundation of any strong sustainability position, we express our debt to William Rees and Mathis Wackernagel's Ecological Footprint Analysis (EFA), while simultaneously differentiating our approach from theirs and in particular Rees and Jennie Moore's more recent implementation of their One-Planet Living (OPL) technique.

\section{TOWARD A THEORY OF SUSTAINABLE CITY-REGIONS}

Today, a consensus on the meaning of sustainability has been all but lost to a cacophony of operational understandings being fitted to often narrow research programs of disciplinary sub-communities. In an earlier day, the meaning and scope of sustainability for first-generation scholars and policy makers began with the sustainability tripod (or stool) or triple bottom line. Here, sustainability was depicted either as a stool with three legs or as three overlapping circles (Venn diagrams) that signify ecological health, economic well-being, and social equity. As this image was popularized, though, a certain conceptual slippage took place that blunted its implicit critique of industrial-technological society and came to erase its incorporation of social justice.

A strong, vibrant, and compelling understanding of sustainability has thus been obscured by a definition that ironically launched the global sustainability movement and became a mantra for enthusiastic local activists and well-meaning policy makers promoting sustainable city endeavors throughout North America and other continents. This definition, rendered in the famous Brundtland Commission report, Our Common Future, declares that sustainable development is "development that meets the needs of the present without compromising the ability of future generations to meet their own needs" (WCED 1987). This understanding largely served as a minimalist definition around which social consensus might coalesce to initiate broadly based and loosely organized programs.

The Brundtland Commission definition also blurred a distinction that is crucial in the debate over sustainability - namely, the difference between growth and development. While some advocates of sustainability programs use the terms interchangeably, Daly and Cobb clarified the distinction by defining "growth" as the "quantitative expansion in the scale of the physical dimensions of the economic system," while defining "development" as "qualitative change of a physically nongrowing economic system in dynamic equilibrium with the environment" (1989: 71-72). 
Contrary to the growing malaise and drift within the sustainability community away from an integrated conceptualization of sustainability, we sought to overcome the essentially contested nature of sustainability by re-founding the concept and condition upon a strong, as opposed to a weak, definition of sustainability (see Box 1.1). For us, sustainability is a "local, informed, participatory, balance-seeking process, operating within its Sustainable Area Budget, exporting no harmful imbalances beyond its territory or into the future, and in so doing opens spaces of opportunity and possibility."

\section{BOX 1.1 OPERATIONAL DEFINITION OF SUSTAINABILITY}

Sustainability is a local ...: Sustainability needs a place to happen. Although problems aggregate and become manifest on a global scale (e.g. ozone depletion, global climate change), offenses to the environment are produced locally. When dealt with locally, where 'local' means the city-region, the neutralization or reuse of all harmful byproducts must be considered part of the price of doing business. The earlier history of our civilization is the history of city-regions - largely autonomous towns that gained virtually all of their material needs from their local countryside and had to maintain the quality of the countryside in order to sustain their way of life. From this perspective, sustainability can only happen at the scale of the city-regionthe largest scale capable of addressing the many urban architectural, social, economic, political, and other imbalances besetting the modern world and simultaneously the smallest scale at which such problems can be meaningfully resolved in an integrated and holistic fashion.

... informed ...: In order to be able to maintain the quality and the productivity of the local region and its countryside one must understand the consequences of the metabolic activities occurring within the city-region. Earlier towns operating within a largely closed system received rather rapid feedback as to the consequences of their activities. Because almost all activities manifested locally, causes and effects related to those activities were quickly understood. When imbalances threatened the city-system, they were noted and adjusted locally. In the modern world there are effectively no local boundaries and positive activities at a small scale may well have negative consequences at larger scales. By using modern means, however, we gain powerful tools both to design and monitor major energy and material flows and to model the projected implications of different processes we might choose to include in our city-region. 
... participatory...: Sustainability is a process by which a local community can decide how it will afford to live within its natural budget and the limits of its own creativity. Such a process starts with the principle that sustainability is non-negotiable, where in principle everything else is negotiable. That means that all participants in the process must agree that the health, equity, and viability of the city-system are the preconditions for any other decision. Second, as the sustainability process proceeds, stakeholders increasingly realize that they share a common destiny and that significant synergies will result from their creative encounters and negotiations. Through many iterations, the city-region becomes understood more as an urban ecosystem and less as an adversarial, zero-sum game. Eventually, the players become partners and more focused on building common wealth.

... balance-seeking process ...: The problem with our existing economic system is that it has no built-in mechanism to insure its own long-term survival. It is not designed to pursue balance. As noted above, natural ecosystems in early stages of succession are also designed to maximize production at low levels of diversity, but as such systems mature, and organic material accumulates, the emphasis shifts away from production and toward maximizing diversity, resiliency, and maintaining internal balances. This needs to be the model for human ecosystems.

... operating within a Sustainable Area Budget (SAB) ...: In the past, nature was assumed to be so vast as to be able to comfortably absorb any and all offenses that humankind's activities dumped onto it. It is now clear that we have long since exceeded many of nature's capacities. The Sustainable Area Budget is our concept for the natural budget in land area, available for each city-region to support its way of life. A simple determination of the SAB for a city-region goes something like this: simply divide a country's total land area by its population and multiply by the number of people in the city-region.

... exporting no problems beyond its territory or into the future: The key idea here is that when the prior part of this definition is realized, such a city-region will effectively export no problems beyond its territory or into the future. On the other hand, even this circumstance is negotiable, given our Fifth Operating Principle for Sustainable Cities, which states that "imbalances are to be negotiated upward (outward)." This means that in some cases an imbalance may be exported from the city-region, but only if its rebalancing can be accounted for by an agency beyond the scale of the city-region. 
... and in so doing opens spaces of opportunity and possibility. In establishing an engaged citizenry in the evolution of the city, its institutions, and its ongoing governance, they will develop a strong emotional co-ownership and even love for the city they have collectively birthed. Such an ongoing, creative engagement, rooted in trial-and-error experimentation and a rich synthesis of competition and collaboration, will create an overarching ethos that opens spaces of opportunity and possibility in the ongoing life of the town, into the future.

Source: Dumreicher et al. (2000).

Fortified with this operating definition, we sought to contribute to the evolving national and even global debate over the meaning, scope, and focus of sustainability. This reformulation contributed to our framing of parts of the Aalborg Charter (1994), a commitment to building sustainable cities in Europe that was eventually signed by over 400 cities on that continent. It also inspired the crafting of a rubric of urban sustainability to counter minimalist definitions of sustainability like that of the Brundtland Commission, and to cut through the growing popularity and substitution of vague "green" language for strong and more precise (and demanding) sustainability terms (see Box 1.2).

The importance of this task stemmed from the fact that "green" is typically associated with individual products and processes that seek to "pick the low-hanging fruit" available in seemingly plentiful supply in modern industrial societies like yours and mine. Second, green practices are ideologically safe practices that do not fundamentally disturb the driving forces of economic growth and corporate profit-making tacitly built on planned obsolescence. Third, "going green" distinguishes itself from sustainability in that conceptually it balances precariously on one leg (either environmental health and well-being or, more often, economic vitality) of the sustainability tripod, while routinely neglecting social justice or equity.

\section{BOX 1.2 WORDS MATTER}

A number of words and expressions that have come into common usage as part of the sustainability lexicon have played an unfortunate role in hindering the successful pursuit of sustainability. These concepts must be critically examined, better defined, and more precisely parsed if sustainability as a socio-political project of twenty-first century cities worldwide is to be realized. Consider the following concepts so often used interchangeably:

Green: This term typically means anything that carries a small measure or tinge of green - an ecological, natural, organic, not artificial, quality. It is 
often applied to anything that has at least one redeeming feature, component, material, or use associated with the natural or built environment. This characteristic is often sufficient to give a product and/or its use a seeming positive ecological value. More critically, it is a product marketed as "green" but through a process of "greenwashing" that at best modestly advances the economic or environmental leg of the sustainability tripod, but never the social equity leg.

\section{Sustainable/Sustainability:}

1. When sustainable or sustainability carries the minimal attributes of "green," it is a meaningless exaggeration or mere puffery camouflaged by false claims that it wears the mantle of a term assumed to have substantial meaning.

2. These two concepts are widely considered to be "essentially contested constructs," triggering wide disagreements about their true meanings that ultimately remain to be adjudicated and resolved. When treated in this fashion, sustainable and sustainability are often simply operationalized to carry discrete characteristics whose substantive core meanings are put out of play and treated as simply subjective.

3. Whenever sustainable is used as an adjective, it is typically being used incorrectly (except in the case of "sustainability oriented," "sustainability driven," or "sustainable city-regions"). Thus, a "sustainable" material, object, product, entity, or process should all be considered misnomers. At best, they are merely being called "green"; at worst, they are making the claim that the consumer is making a small, but palpable contribution to the survival of our current society and the future of our children and grandchildren by buying or using this product.

\section{Weak Sustainability:}

1. Weak sustainability is any program or action that offers at least some small scale, local, or short-term ecological, social, or economic benefit, regardless of what the larger, wider, or long-term consequences may be to the environment. This term is what almost everyone actually means whenever they use the term sustainability.

2. Everything that is viewed as not unsustainable.

3. Every component or action that is part of a strong sustainability program or process is either a weak sustainability or a sustainability neutral action or method.

4. Sustainability indicators treat metrics or yardsticks as ways of "moving toward sustainability" or making things "more sustainable." They should really be called "unsustainability indicators," since they actu- 
ally indicate the seeming rate at which a system is approaching sustainability or regressing further out of balance. Because sustainability is a process, not a path, one cannot move toward sustainability. One is either operating according to sustainability principles or one is not.

\section{Strong Sustainability:}

- Strong sustainability recognizes the difference between growth (quantitative increase) and development (qualitative increase), opting for the latter over the former. Furthermore, it acknowledges that the basic unit of sustainability is the city-region and that sustainability is a process, not a pathway.

- Further, it seeks to generate local-regional sustainable policy making metaphorically around the model of the Sustainability Game involving multiple scenario-building as the driving process for generating sustainable solutions for urban development, land-use, site selection, etc.

- Strong sustainability then is the name of the process of generating a new, or converting an existing, city-region into a constellation of socio-economic and political processes operating under conditions that conform to the following definition: "Strong Sustainability is: a Local, Informed, Participatory, Balance-Seeking Process, Operating within its Sustainable Area Budget, Exporting No Harmful Imbalances beyond its Territory or into the Future, and in so Doing Opens Spaces of Opportunity and Possibility" (Dumreicher et al. 2000).

\section{Strong Sustainability and its Relationship to Weak Sustainability:}

- Strong sustainability and weak sustainability are two essentially different referents that share the same term but are vastly different in meaning. They share the term sustainable/sustainability. This dual usage causes serious problems and confusion, the major one of which is to hold back the development of strong sustainability and its trust and acceptance by both the scientific community and the larger public. Until or unless they are understood as different concepts with different names, this problem will persist to society's disadvantage.

- We have sometimes called one of them by the term "weak sustainability" but, on the other hand, that sounds disparaging when it is not meant to be so. What we rather mean by weak sustainability is "sustainability-oriented," or "sustainability-driven" entities. What these weak sustainability synonyms connote is that such a substance, material, component, product, action, project, approach, or local process is one that qualifies as sufficiently beneficial or at least benign, when consid- 
ered in the context of its local use. Simultaneously, they lack characteristics that are inherently irremediable and can therefore be used as a part of a larger strong sustainability regime, program, project, or process. In fact, every strong sustainability process will be wholly composed of, or entirely consistent with, sustainability-driven or sustainability-oriented (i.e. "weak sustainability") components.

No less important, "green" is popular and easy because it connotes quick and inexpensive steps to make the world less unsustainable-i.e. by generating tactics for reducing the environmental impact of human activity, agricultural and industrial production, and our built environment. The differences between "green" and "sustainability" then are not a matter of "mere semantics." Nor is the question of the appropriate scale for achieving sustainability.

As advanced in our "Sustainable Cities Manifesto," the city-or, better, the city-region - is "the largest unit capable of addressing the many urban architectural, social, economic, political, natural resource, and environmental imbalances besetting the modern world and, at the same time, the smallest scale at which such problems can be meaningfully resolved in an integrated and holistic fashion." Even more, "it is also the political Archimedean point for fostering the process of aggregating human beings into a relatively small area and providing the necessary forum for a civic life, serving as the medium for decentralizing and localizing economic production and commerce and thus preserving the social surplus of the local economy for the community's self-sufficiency and self-enhancement" (Yanarella and Levine 1992b: 305). Is it any wonder that the Chinese national government has realized that its future, its country's political economy, and its basis for a harmonious society are grounded in its cities and, in particular, its eco-cities?

Sub-urban scales fail because they cannot provide all of the conditions and resources for sustainability. Supra-urban scales fail because they are too complex and mean the "sustainability quotient" cannot truly be calculated. By the mid-1990s we had expanded the scale to incorporate the region or rural "partnerland" as a necessary component with the city to assure an agricultural base to the city population's needs. In sum, the city-region at the Goldilock's scale - not too small and not too big, but "just right"!

Another element of the sustainability puzzle is the question of determining how to fashion a yardstick or metric for measuring sustainability. If the city-region is the proper scale where the many energy, transportation, and other imbalances can feasibly be brought into balance, a sustainability yardstick must be found. Several alternatives present themselves. The first is the sustainability indicators approach, a method that was readily adopted by city councils and planning divisions to assess discrete programs comprising 
their urban sustainability agendas. It even seems to be the preferred basis for national Chinese criteria for evaluating the success of its eco-cities.

The virtues of sustainability indicators are that they point to intuitive dimensions of sustainability (transportation, energy, food, land-use, architecture, etc.); clarify stated goals and desired outcomes; and assure that what gets measured and evaluated gets implemented and supported. Their drawbacks are that in favoring the practice of "picking the low-hanging fruit," they make each new step harder, more costly, and more politically intractable. In addition, at no point on any of the separate scales or dimensions is there a place where sustainability can be said to exist. Finally, this approach forgets that sustainability is not a quantity to be measured along a pathway; it is an ongoing integrated and systemic metabolic process to be established and continually rebalanced.

Ecological footprint analysis is the other approach that public decision makers and planners have embraced to measure sustainability progress. A method championed by Mathis Wackernagel and William Rees, it involves calculating the aggregated territory appropriated (consumed) by current human activities. It allows one to estimate within the defined parameters of a person, a neighborhood, a city, region, nation, or the globe how big a footprint is being made by the consumption of natural resources. The ecological footprint has been extolled because it is a highly quantitative method and extremely effective as an analytical tool for assessing the environmental load of human activity relative to the earth's carrying capacity. Both metaphorically and visually, the approach is powerful and compelling as an educational tool. But, as utilized, it can only indicate how much less unsustainable a city or nation becomes as it reduces its ecological impact through natural resource conservation or energy efficiency or by embracing renewable and solar technologies to replace fossil fuels.

By contrast, the Sustainable Area Budget (or, as Wackernagel and Rees call it, the "fair Earthshare") involves a paradigm shift from lowering our environmental loads on the ecosystem to collectively restructuring our places, our processes, and our lifestyles within a boundary. Its logic amounts to this: If each city-region were to have a budget, a land-based budget, from which to satisfy its needs now and into the future, then it would have a clearer understanding of its resources and its limitations. Such a Sustainable Area Budget could be calculated in the following manner. The land budget of a city-region is the same fraction of the Earth's total land area as its population is a fraction of the Earth's total population. This means that each resident on Earth carries a claim to the balancing potential of his/her fraction of the Earth's land area divided by its population. In even simpler terms, we can start with the SAB of each person on earth as $1 / 7.8$ billionths of the calculated land budget comprising all the earth's natural resources converted into land area on a reasonable basis and 
that number is multiplied by the number of people and person equivalents in the city-region.

One implication of the SAB is that with a fixed area budget the stakeholders of a city-region would in principle be free to negotiate their way of life within the limitations presented by their locale and their own culture and creativity as long as they do not export any harmful imbalances beyond their SAB or into the future. Its virtue is that for the first time a clear and relatively precise basis upon which to conduct a local sustainability process would exist.

The SAB concept is likely to strike one as simple in principle, but far-fetched in practice. On the one hand, it is not strikingly different from the strategy and calculations that Rees and Wackernagel have used in determining the basis for generating ecological footprints. If we turn the ecological footprint on its head, we have the fair Earthshare, which is very close in principle to a Sustainable Area Budget. Moreover, arguably the best strategy for tackling the climate change problem on a global scale-Aubrey Meyer and the Global Commons Institute's Contraction and Convergence approach - also begins with estimating the carbon budget/person in the similar way (GCI n.d.). On the other hand, such a formula blinks at the issue of rising population, which leads to an ever-shrinking fraction of a land or carbon budget. On the other hand, there may be a simple policy fix. In order to initiate the process, the rising population basis for the SAB calculation could be based upon the global population at the date of the commencement of each sustainable city project, incentivizing an earlier beginning of each project.

The Sustainable Area Budget is a necessary component of a multiple scenario-building process we have called the Sustainable City Game. On one level, the Sustainable City Game is very much like a typical role-playing game. It has its rules, boundary conditions, strategies and tactics, and ultimate goals. On another level, this balance-seeking game can — and should — be transferred into real-life democratic processes in actual urban decision making. Instead of players of a game, local citizens and other stakeholders would become partners in a process directed toward confronting the conditions surrounding real urban projects. An advantage of the real-world Sustainable City Game is that each proposed scenario would be assembled and disassembled, structured and destructured, many times through successive iterations during the design process before it is actually constructed.

Initially, this policy making process is played at a simple level with the players who may be both lay people or experts in various disciplines or industries attempting to follow their ideas or their self-interests to construct city models or, more likely, partial models of activities (manufacturing, energy production) or places (neighborhoods, schools, piazzas) that may be of interest to them within a hypothetical city. As the "game" proceeds, almost anything may be proposed, even activities normally thought to be unecological (e.g. pol- 
luting, manufacturing activities). In the Sustainable City Game any proposed model or solution, to be viable within this process, either must negotiate local balance-seeking relationships with other activities or must find a linkage with larger scaled systems or activities that assume the responsibility for rebalancing any negative consequences of the local process.

Several factors make a sustainability process workable. First of all, such a process starts with the cardinal "rule of play" in the Sustainable City Gamenamely, that while at least in principle everything else is negotiable, sustainability itself is non-negotiable. This is where the Sustainable Area Budget comes in: the SAB serves as the balancing point around which game play takes place. Second, as the Sustainable City Game proceeds, the stakeholders are likely to increasingly take leave of their anchoring self-interests and come to realize that they share a common destiny and that destiny is contingent upon a balance-seeking urban metabolism within a fixed land budget. As a result, significant synergies will tend to emerge from their creative encounters, negotiations, and cooperation. Through many iterations, the city-region becomes understood more and more as an urban ecosystem and less and less as an adversarial, zero-sum game. Early in the process, the players will realize that while they enter the game with the intention of maximizing their own needs and the needs of the sectors they represent, their greatest successes can only come when the city as a whole prospers. Overcoming their adversarial stances will foster synergies and partnerships as they seek to build common wealth.

Integral to the Sustainable City Game as a game and as a policy tool is the Sustainability Engine ${ }^{\mathrm{TM}}$. The Sustainability Engine ${ }^{\mathrm{TM}}$ is the artificial intelligence of the Sustainable City Game. Both during the design process and in the governance and management of the city-region, the Sustainability Engine ${ }^{\mathrm{TM}}$ houses the energy, material flows, and process models that are studied and tested in order to move the game forward in the development of the city. As the city, its processes, and industries are studied, the Sustainability Engine ${ }^{\mathrm{TM}}$ provides frequent feedback on the ongoing state of the system and indicates the sectors where it is out of balance. Thus, the Sustainability Engine ${ }^{\mathrm{TM}}$ is a tool capable of modeling the state of balance of a city system and providing the means for assisting in the rebalancing process of the overall metabolism of the city, as well as storing and providing feedback about the city scenarios as three-dimensional models.

One feasible way of conceptualizing the general architecture of the Sustainability Engine ${ }^{\mathrm{TM}}$ has emerged. As early prototypes of the Sustainability Engine $^{\mathrm{TM}}$ have developed, three elements have been presented and are tightly interconnected: (1) a scenario builder, which sets up the context of experimentation and houses the critical data and partial models that may be used in multiple scenario-building; (2) a 3D town visualizer, which creates a mirror world or virtual model of the setting within which the city scenarios exist; 
and (3) a sustainability impact forecaster, which projects the consequences of designs, actions, and tentative solutions suggested by one or another of the scenario-building stakeholder teams.

An overview of the state-of-the-art in urban planning software will show that the Sustainability Engine ${ }^{\mathrm{TM}}$ has had many predecessors. Its origins go back at least to the early 1980s in the efforts of Dr. William Jepson to design software to facilitate the work of the UCLA Urban Simulation Team. The team's pioneering work was the first such effort to fashion methodologies and computing tools for constructing realistic 3D models of large areas of the city of Los Angeles.

More recent advances in achieving similar goals to that of the Sustainability Engine $^{\mathrm{TM}}$ have been made by the Environmental Simulations Center's CommunityViz software program. CommunityViz is a community support decision making program that comprises three core elements: a Scenario Constructor (now Scenario 360), which takes geographical and other data to model the physical layout and infrastructural conditions of the community problem; a 3D Sitebuilder component that develops a fully interactive real-time $3 \mathrm{D}$ environment allowing participants to visualize, modify, and refine alternative scenarios; and a Policy Simulator, which permits stakeholders to examine the impacts and consequences of each alternative scenario generated. It is predominantly used for urban, land-use, and transportation planning, as well as natural resource management.

The realization of the Sustainability Engine ${ }^{\mathrm{TM}}$ until recently has been hobbled by constraints on available technology and software. That is, the structure and demands of the Sustainability Engine ${ }^{\mathrm{TM}}$ have remained beyond the reach of advancements in 3D visualization, GIS, and policy simulation technologies. A giant step forward in overcoming these limitations occurred when Arizona State University (ASU) under the leadership of its president Michael Crow built its Decision Theater. The ASU Decision Theater has been touted as a world-class research facility and decision lab for engaging diverse stakeholders in exploring collaborative ways to confront difficult economic development, energy, and natural resource issues by exploring alternative scenarios. By cutting edge visualization, decision systems science, and simulation and solutions tools, decision makers are now better able to address today's mounting challenges and anticipate and plan for tomorrow's emerging problems. Because Arizona's built environment is at the mercy of often distant rivers and aquifers to meet its water needs, the multiple scenario-building game, WaterSim, has been played numerous times to investigate and predict alternative approaches to aligning population and land-use planning with possible water futures Arizona and the southwest United States may have to face.

The last two innovations to the design and implementation of sustainable city-regions are the Sustainable Urban Implantation (SUI) and the Rural 
Partnerland. These two features of the theory or strategy of sustainable city-regions were originally developed in a project commissioned by the vice-mayor of Vienna, Austria to heal a wound in the western part of the city opened by the Westbahnhof railway station. Previous attempts by European urban planning/architectural teams to solve the problem of stitching back together the scar created by the railway tracks leading into the Westbahnhof station that effectively split the area in two had failed. (For the full case study and project report summarized below, see Yanarella and Levine 2011: 165-182.)

Our solution was to build a Sustainable Urban Implantation over the railway tracks that created a multi-layered urban implantation - a City-as-a-Hillinspired by the structure of the medieval Italian hilltown. As we shall see (Chapter 6 and Appendix), the Sustainable Urban Implantation archetype offers many advantages and many supports for sustainability processes and actual implementation that would be almost impossible to achieve using conventional planning processes and urban forms. In this application, the SUI - being inherently three-dimensional — would be able to bridge over the rail yard, unite the now severed communities on either side, create a dynamic new neighborhood, and offer many other advantages that would not be possible working from a conventional street grid.

Since the SUI was a total urban construct and its design has no open ground of its own, the implantation was studied to be linked with a rural partnerland, dedicated to being the food, material, and energy provisioning component of the sustainable implantation and to become the major part of the SAB in rebalancing the energy and material flows of the city-region. On this land, the agriculture and energy from solar regenerative sources would be negotiated with its urban counterpart. The implantation, together with its rural partnerland, would constitute a contained sustainable city-region sharing a combined Sustainable Area Budget.

Within the Vienna Fifteenth District, an extensive network of social, ecological, and economic initiatives and enterprises already existed, but the actors were largely unaware of the importance and the value or extent of this network. Individuals often consider themselves as a powerless minority who, at best, can only hope to overcome some of their own most pressing problems. In the process of establishing the network, the actors would come to see the relationship between their own small spheres of activity and that of the dynamic and increasingly powerful whole.

In activating the city-region principle, an early step was to establish partnerships between well-defined structures in the town district (District 15) and the region (Mistlebach), including the political, administrative, cultural, economic, and agricultural institutions of both. The concept of a marketplace is extremely useful in the establishment of new opportunities. The marketplace 
of ideas, as well as of goods, services, and cultural exchanges, becomes the generator of an expanding social network for the creation and utilization of available goods and services. Such a program was put in place, involving, for example, the farmers of Mistlebach and the grocers of the Fifteenth District. So, in contrast with many Chinese eco-cities that are often built as greenfield sites some distance from the historic city, this approach makes it possible to build eco-city implantations on brownfield sites within the historic city that can be paired with a rural partnerland currently used for farming and other rural practices and that could extend the urban sustainability concept from within the historic city and outward to the countryside in a mutually beneficial arrangement.

\section{REES, WACKERNAGEL, AND MOORE: WHERE WE AGREE}

Recently, the ecological footprint/fair Earthshare research program inaugurated by William Rees and Mathis Wackernagel has taken a step-level jump in refining and applying its sustainability metric (the fair Earthshare) in Jennie Lynn Moore's recent doctoral dissertation (Moore 2013) and elaborated in the collaborative work of Moore and Rees (2013). Using Vancouver's fair Earthshare, this emerging body of research seeks to calculate the part of that sustainability yardstick attributable to various urban policy domains (energy, food, transportation, housing, consumables, water) and then to offer means by which Vancouverites might live within their fair Earthshare of 1.7 gha/person and attain One-Planet Living (OPL).

Acknowledging previous criticisms of the concept of the fair Earthshare and its underlying approach to achieving strong urban sustainability, Moore uses the calculations of the Wackernagel-led Global Footprint Network to determine the fair Earthshare of Vancouver and its current ecological footprint (2.342 million gha total, or over 4 gha/person). (Note: gha or global hectares is the globally averaged sample of arable land.) She then calculates the part of that sustainability yardstick attributable to various urban policy domains in order to offer means by which Vancouverites might live within their fair Earthshare of $1.7 \mathrm{gha} /$ person. The exercise, subsequently published in two venues (Moore and Rees 2013; Rees and Moore 2013) presents an impressive approximation of what changes in policy spheres need to be introduced with democratic consent by key policy makers and planners to reach OPL there.

Before elaborating on their method, it bears re-emphasizing that Moore and Rees' fair Earthshare and Levine and Yanarella's Sustainable Area Budget are built upon the same two principles. Both work from the idea that achieving sustainability is based on each person living with their equitable or fair Earthshare of global biocapacity. In addition, each seeks to determine the means to reduce 
the excessive footprints of human beings in their social or aggregate settings to live within their ecological means or Sustainable Area Budget. The fundamental difference between the two is that when the fair Earthshare calculus is applied to a city, Rees and Moore seek to generate reductions to bring the ecological footprint of that designated city in line with the appropriate land budget of the physical city, while the Sustainable Area Budget (see Yanarella and Levine 2011: 63-74) incorporates either the surrounding countryside or what we call a rural partnerland to satisfy the land-based or agricultural demands of the city's population.

Most striking and a clear advance beyond theoretical arguments is the methodological approach Moore and Rees develop to generate the data for calculating the various consumption components driving Vancouver's ecological footprint (EF). These EF consumption components-food, buildings, consumables, transport, water, and services - comprise Vancouver's EF land-use matrix, leading to a total of 2,361,792 gha or 4.09 gha/person. Proportionally, of Vancouver's overall EF, food represents 52\%, transport 20\%, buildings $16 \%$, consumables and waste $12 \%$, and water effectively $0 \%$. These components are further broken down into sub-categories - i.e. the food component is separated into: fruits and vegetables; meat, fish, and eggs; stimulants, such as coffee, tea, sugar, and cocoa; grains; oil, nuts, and legumes; dairy products; and beverages - and their EF calculated by food type.

No less admirable and convergent with our urban sustainability approach is Moore and Rees' use of data from fair Earthshare societies in Latin America, Europe, Asia, and Africa, which are lower-consumption countries living within One-Planet Only that "enjoy comparable longevity but have somewhat larger households and lower per capita calorie intake, meat consumption, household energy use, vehicle ownership, and carbon dioxide emission than average world citizens" (Moore and Rees 2013: 42). Our strategy has similarly looked to medieval hilltowns to discern both urban architectural and lifestyle differences with today's sprawling, consumer-oriented cities that might point to clues that might inform the restructuring of these high-consumption and profligate towns and cities. Moore and Rees undertake this comparison between high-consumption societies and fair Earthshare ones to starkly represent the sustainability gap between the two and press for high-income consumer societies striving to seriously engage the necessary task of living within the one-planet criteria and possibly learn cues or lessons from these fair Earthshare societies. (In our own work in Italian hilltowns and in rural Chinese villages, which either historically or currently have lived within their SAB, we have studied and using system dynamic methods have modeled the actual metabolism of these places. We used the term "proto-sustainable" to describe their way of life, as they operate within their SAB, but at a level of material comfort and consumption that we "moderns" would be unlikely to accept. Yet 
Table $1.1 \quad$ The pleasures of the Paleolithic life

\begin{tabular}{ll}
\hline$\bullet$ Spending the day outdoors & $\bullet$ Finding a mate \\
\hline$\cdot$ Walking and running & $\bullet$ Raising kids \\
\hline$\cdot$ Looking for things & $\bullet$ Looking at fire \\
\hline$\bullet$ Making things & $\bullet$ Seeing by moonlight \\
\hline$\cdot$ Throwing rocks & $\cdot$ Killing animals and being killed by animals \\
\hline$\cdot$ Cooking and eating & $\bullet$ Making beds at night \\
\hline$\cdot$ Talking and listening & $\bullet$ Exploring new land \\
\hline$\cdot$ Singing and music & $\bullet$ Feeling emotions, including terror, religion, right \\
& and wrong, etc. \\
\hline
\end{tabular}

- Dancing and sex

Source: Robinson (2007).

these places clearly demonstrate that sustainability within budget is possible and if we work within a robust decision making process as intended with the multiple scenario-building process we can live well by living sustainably.)

In her dissertation, Moore develops the notion of "lifestyle archetypes" of such societies, as well as intentional communities choosing to live in sustainability-oriented ways, where these examples of lifestyles illuminate what OPL would look like and serve as something of a normative model and offer guidelines for places like Vancouver.

Somewhat convergent with this tack, noted science fiction writer Kim Stanley Robinson returned to the issue of cultural and lifestyle change after completing his Science in the Capital climate change trilogy by rejecting the consumer economy founded upon unlimited growth in a finite earthly system and once again highlighted the advantages flowing from living the values and fulfilling the needs of our Paleolithic inheritance. As he argued, this is "not a matter of lowering your standard of living. The hyper-consumption lifestyle has not made us happier, healthier. [It has] just made us more frantic. The more you do it the less enjoyable it is." He recommended instead that we turn to the commonplace enjoyments of the Paleolithic life (see Table 1.1) and actualize ourselves as the primates that we are (Robinson, 2007).

The point is not that these simple forms of enjoyment should lead to a "back to the Paleolithic era" lifestyle, but that modern correlates to the primate level of our sources of happiness can serve as guideposts to One-Planet Living without deficit or sacrifice of human flourishing.

We also agree with Moore and Rees' conceptualization of the relationship between and among the conventional representations of the three realms constituting sustainability: economics, equity, and ecology. Moreover, Moore and Rees reject corporate interpretations of these systems that treat the economic 
system as the more encompassing sphere. As they make abundantly clear, this flawed approach "masks the hierarchical context in which the dimensions exist and thereby avoids confronting the reality of the economy's and society's absolute dependence on global ecosystems" (Moore 2013: 18). Indeed, like they do, we treat economy, society, and ecology as a nested hierarchy wherein the social and economic reside within the more comprehensive envelope or enclosure of the world's ecosystem. On the other hand, although we live in an increasingly globalized world for better or worse, we also insist that sustainability is a local process. Sustainability has to happen in a place with both local boundaries and local balancing.

\section{REES, WACKERNAGEL, AND MOORE: WHERE WE DISAGREE}

Even as Moore's and Rees' work provide important innovations and breakthroughs in the research program to conceptualize and quantify the method and substance of the fair Earthshare and One-Planet Living, our convergent research program would seem to help address some of the shortcomings and deficits in the Moore and Rees approach so far delineated.

\section{From Technocratic Planning to Discursive Democracy}

Critical to differentiating the Moore/Rees approach from the Yanarella/ Levine one are the differing logics or strategies governing their attitudes and orientations. The former is grounded in a logic of reduction through a process of top-down planning while the latter is based upon a logic of construction, experimentation, and collaborative negotiation manifested in an interplay of top-down and bottom-up design. Put most starkly, we seek to promote a sustainability process that moves from the Moore/Rees propensity to embrace technocratic planning to our emphasis on discursive democracy. Let us elaborate.

First, Moore and Rees place a great deal of faith in Canada's more technocratic planning orientation, leaving the active participation of the public citizenry as secondary. That is, citizens in Moore and Rees' decision making framework have no meaningful role in making choices among the alternative means for reducing Vancouver's ecological footprint to its fair Earthshare. Public scrutiny and support only take place after the calculations have been made by technical specialists, who-in the process of devising scenarios for EF contraction - conferred with planners and policy makers concerning the political feasibility of such extensive proposed reductions. Far better would be to use the participatory/planning aspects of the Sustainable City Game to involve citizen stakeholders in collaboration with experts and planners from 
the beginning. Using the process of alternative scenario-building to formulate highest common denominator scenarios then would more likely generate far greater legitimacy, public credibility, and acceptance.

One of the problems encountered by the outcome of Moore's and Moore and Rees' EF component calculations and reduction strategy and scenario for bringing Vancouver in line with One-Planet Living is the levels of reduction of its various consumption domains necessary to reduce the material and energy flows to a "one-Earth" level. Under Baseline 1 (Moore 2013: 191), these reductions would mean, among other things:

- adopting a total vegan diet (abstaining from fish, meat, eggs, and dairy products);

- refraining from flying as well as owning and operating private motor vehicles;

- switching to renewables to achieve zero $\mathrm{CO}_{2}$ emissions of the entire building stock; and

- eliminating all consumption of paper and plastics.

At the scale of the individual or family, these sacrifices would prove too onerous or even unacceptable to most people, not to mention most major corporations. Arguably, few would be willing to subscribe voluntarily to such stringent reductions and no voting majority would likely ratify any of them. Before such voting happened, elected officials responsible for leading a campaign to institutionalize one-planet only levels of throughput would likely be recalled, voted out of office before the lengthy mobilization campaign was completed, or forced by mounting public protest and pressure to withdraw their political support for the effort.

Another problem with reducing levels of consumption/throughput sector-by-sector and combined to add up to a one-Earth overall urban system-Moore and Rees' basic approach — is that this strategy does not make a city sustainable unless it is performed in a highly organized and systemic way. Indeed, unless it is systematically pursued across policy realms, it will fail to take into account the many synergies that could be achieved between and among the different domains. To illustrate, energy and transport are not discrete areas where reductions take place in isolation from one another; rather, reductions and efficiencies in one may bring benefit to the other, may increase the other's load on the environment, or may even destroy the functionality of the city-system. Under different choices, other scenarios can give rise to greater reductions of the combined consumption realms than would seem to be achieved separately.

By contrast, our strategy approaches the achievement of a sustainable one-Earth system from the opposite direction. One of our approaches involves 
a process of synthesis, rather than discrete reductions in individual policy realms, as proposed by Rees and Moore. The other involves building the town system up from the beginning. The first strategy through synthesis involves institutionalizing the Sustainable City Game/multiple scenario-building process in the planning of existing cities where citizen stakeholders are brought into the real-world policy game. In this way their interests, values, and goals feed the game-playing nature of the planning process for attaining the one-planet living target by engaging in the process of generating multiple scenarios for achieving reductions, taking the best solutions for those alternative scenarios and using them as the resources for higher levels of synergistic reductions. Through many iterations bounded by the rules of the game, an OPL is achieved or closely approximated.

In the second approach, citizen stakeholders aided by specialists in various policy domains try to resynthesize the original town in a sustainable incarnation, first, reducing the physical town to zero - that is, to just the original town site - and then reinserting all the infrastructure, major institutions, and facilities required for having anything like the town to actually exist. In the process of reassembling the town, piece-by-piece, we also track the effect that each new (or old) addition subtracts from the town's allowable SAB. As envisaged, all too soon as we attempt to recreate the town, which we love as it is (except for its unsustainability), we discover that we have exhausted the available SAB long before the full town has been reconstituted. Since the game we are playing is to reconstruct the town keeping what we like most, but being willing to change or modify other aspects to construct a town with a balanced metabolism and a reduced material economy, participants in this version of the multiple scenario-building game/process start to make changes to how we have been reconstructing the town so as to lower its footprint, both locally (e.g. individual buildings) and globally (e.g. energy, food, and transportation systems).

The trouble with the footprint reduction exercise like the one proposed by Rees and Moore, is that a point of diminishing returns is quickly reached (see Yanarella and Levine 2011: 53-62). In a process aimed at incrementally reducing footprints, one typically picks the easiest and initially most gainful reductions and efficiencies first, but as one goes deeper into the exercise, each step becomes more difficult than the one before, yields less reduction for the pain or effort expended, and elicits more and more opposition as people's (desired) lifestyles or "business as usual" pursuits are increasingly threatened. This overall process quickly stalls at a point far below necessary levels of reduction with the goal of a viable city system within its SAB not having been reached.

Over the longer run, what makes matters worse is that with all the low-hanging fruit having been picked, additional and more ambitious footprint reduction programs become increasingly more costly and politically 
intractable, making the goal of sustainability hopeless. One could even say, for example, that energy/resource conservation - generally viewed as a positive technique - ultimately becomes a negative because its further unrealizable character turns it into a non-renewable resource. That is, you can change the lighting to LEDs only once and save a lot of money. For the next time greater energy efficiency is needed, the cost of achieving it will be that much higher. In any case, such incremental actions merely slow the drift toward unsustainability.

As the above logic suggests, a different process must be designed to create a sustainable economy and the conditions for a one-Earth system through the participation of the citizen stakeholders involved so that they will be moved to develop an "emotional co-ownership" of both the decision making process, as well as the emerging scenarios that it serves to create. This is in stark contrast to the scarcity and the attendant poverty mentality fostered in a process based almost solely on the elimination of material wealth and comforts that we have come to expect, which creates an image of a new way of living based on all the things that we can no longer have. Contrast that with a process that builds up the possibility of a life of material well-being through the negotiation of competing scenarios each offering benefits to someone or group and aimed at ending up with providing the greatest good for the greatest number. This is what economists refer to as a Pareto optimum, i.e. a condition of economic efficiency where no one can become better off without making someone else worse off. Such a process, we argue, when played out within the limits of the fair Earthshare/Sustainable Area Budget, will result in a much smaller material-energy-throughput economy — one that could not have gained public legitimacy or acceptance, or achieved the outcome of any program driven solely by the Moore and Rees footprint reduction approach.

\section{From Discrete Calculations to the Sustainability AI of Consumption Component Reductions}

Advances in 3D visualization, GIS, BIM, and policy simulation technologies suggest that the expert estimates used by Moore (2013) in deriving approximations of policy component contributions to city-region ecological footprints will eventually be superseded by the kind of Sustainability Engine ${ }^{\mathrm{TM}}$ we envisaged and conceptualized. Moore and Rees and their data collaborators have no doubt developed valuable insights into routinizing the fair Earthshare calculations and these will likely spawn even more accurate technical means and rules of thumb for advancing fair Earthshare/SAB numbers.

Two points are relevant here. First, we highlight these recent developments so as to underline the fact that the advent of a Sustainability Engine ${ }^{\mathrm{TM}}$ is not simply a pipe dream, but a technological capacity that is almost here and will 
soon draw most of its components from off-the-shelf components and data already available or nearly so. Second, we wish to underline the fact that the role of the Sustainability Engine ${ }^{\mathrm{TM}}$ applies to data crunching and rebalancing with the $\mathrm{SAB}$ in a manner that includes the entire city-region or sustainable urban implantation-rural partnerland as it seeks to bring iterations of multiple scenario-building exercises back to the sustainability point appropriate to its land budget (see Yanarella and Levine 2011: chs. 5 and 6).

\section{From Scale-Free Fair Earthshare Approach to the Sustainable City-Region Strategy}

Finally, we question Moore's assertion that cities are an inappropriate scale of sustainability. As pointed out earlier, we staked out the city and then the city-region as the proper scale for strong sustainability. In our Sustainable City Manifesto (Yanarella and Levine 1992b: 305), we argued that the city "presents itself again as the largest unit capable of addressing the many urban architectural, social, economic, political, natural resource and environmental imbalances besetting the modern world ... [and] the smallest scale at which such problems can be meaningfully resolved in an integrated and holistic fashion." As we engaged with colleagues like Krotscheck and Narodoslawsky (1996) in European conversations about methods of calculating a sustainability metric, we revised our conception of the appropriate scale of sustainability and wrestled with the details of what we came to call the Sustainable Area Budget.

In our efforts to refine the Sustainable Area Budget, we introduced the idea of Partnerland (Yanarella and Levine 2011: 73-74) as a necessary component of a sustainable city-region in promoting the notion that a sustainable city-region is the proper scale. Apparently based on Wackernagel and Rees' claim that the fair Earthshare is scale-free (i.e. can be used at any scale from the individual to the global), Moore (2013) and then Moore and Rees (2013) seem to reverse themselves by regrounding their research on the city to calculate its appropriate sustainability metric. More specifically, however, Moore joins Rees (2009) in her dissertation (2013: 12) in distancing themselves from the notion of a "city-region" as the proper scale of sustainability.

Rees' most pointed argument against the sustainable city-region is that the typical contemporary city extends its influence as well as its supply chain far beyond the surrounding region and implicates the city with a set of trade and other relationships that are truly global. Consequently, cities are better conceptualized within their network of dynamic and changing global relations. Cities, then, have "effectively become nodes of consumption in a global urban web of material and energy flow[s], capital flow[s], migration flow[s] and information flow[s]" (Moore 2013: 12, citing Rees 2009, 2010, and 2012). Yet Rees and Moore would seem to contradict themselves when they apply their 
fair Earthshare methodology to the scale of existing cities (and Vancouver, in particular) and seek reductions in their ecological footprints solely within the city's physical boundaries.

Consider the considerable difficulties Rees and Moore get into when trying to confront the food consumption component and the necessary reductions to its footprint. Restricting its scale to the physical city and thus lacking a regional or rural partnerland aspect to their planning strategy, they opt for or are compelled to adopt building provisions for city food around urban agriculture. While an urban agricultural policy has its merits, it has succeeded as a model only under certain exceptional conditions in places like Cuba, where the collapse of the Soviet Union and international embargoes forced Cuban leaders to maximize the production of agriculture in urban land. (For a review of the circumstances and features of Cuba's disciplined switch to food production through a comprehensive urban agricultural strategy, see Chan and Roach 2013; Clouse 2014; Koont 2011.)

This strategic move is surprising, given these estimable researchers' focus on Vancouver. First of all, it is not clear why Moore and Rees could not simply expand the scale of analysis and calculation for a fair Earthshare to incorporate parts of the Greater Vancouver Regional District (now Metro Vancouver) in order to include Vancouver's Agricultural Land Reserve as an alternative to depending upon urban agriculture. Second, as former Vancouver mayor and British Columbia premier Michael Harcourt has persuasively argued, one of the nine critical decisions that saved Vancouver and made it into a leading model of livability and sustainability was the successful political campaign to create and maintain the Agricultural Land Reserve (Harcourt, Cameron, and Rossiter 2007: 56-75). This city-regional framework would overcome many of the conundrums to which the Moore and Rees approach falls prey (see Table 1.2).

To elaborate, in her dissertation when she conceptualizes agricultural production at the neighborhood scale, specifically the Southeast False Creek (SEFC) sustainability-oriented community featured in the Vancouver Winter 2010 Olympics, Moore notes that restricting provision of food within the boundaries of the SEFC site, its population of 11,000-16,000 "would require approximately 146 to 212 ha to produce $75 \%$ of their total vegetable consumption ... assuming equivalent yields," which would be "four to six times the total site area of SEFC (at 36 ha)" (Moore 2013: 207). And again, assigning a minimalist function for citizen participation, the purpose of the SEFC community association in confronting these stringent-to-impossible demands is not to actively negotiate through multiple scenario-building processes to achieve OPL but rather to educate its inhabitants into accepting such draconian restrictions and knuckling down to them (Moore 2013: 210). (Note: in making this 
Table 1.2 Comparison between Moore/Rees and CSC (Yanarella/ Levine)

\begin{tabular}{|c|c|c|}
\hline Issue or dimension & Moore/Rees & CSC (Yanarella/Levine) \\
\hline $\begin{array}{l}\text { 1. Appropriate scale of } \\
\text { sustainability }\end{array}$ & $\begin{array}{l}\text { Scale-free-applies from } \\
\text { individual to globe }\end{array}$ & City-region \\
\hline 2. Sustainability metric & Fair Earthshare & Sustainable Area Budget \\
\hline 3. Planning model & $\begin{array}{l}\text { Logic of reduction and } \\
\text { technocratic planning driven by } \\
\text { technical experts with weak civic } \\
\text { participatory mechanisms }\end{array}$ & $\begin{array}{l}\text { Logic of construction, } \\
\text { experimentation, and } \\
\text { collaborative negotiation } \\
\text { foregrounding maximum citizen } \\
\text { participation and discursive } \\
\text { democratic planning }\end{array}$ \\
\hline $\begin{array}{l}\text { 4. Role of knowledge and } \\
\text { expertise vis-à-vis citizen role }\end{array}$ & $\begin{array}{l}\text { Specialists calculate best } \\
\text { reductions and planners } \\
\text { determine feasibility based upon } \\
\text { technical knowledge and political } \\
\text { judgments with citizens ratifying } \\
\text { pre-selected choices }\end{array}$ & $\begin{array}{l}\text { Specialists serve as handmaidens } \\
\text { of citizen review and proposals } \\
\text { from among alternatives } \\
\text { generated by knowledge } \\
\text { and expertise in an iterative } \\
\text { scenario-building process }\end{array}$ \\
\hline $\begin{array}{l}\text { 5. Method for negotiating } \\
\text { consumption reductions }\end{array}$ & $\begin{array}{l}\text { Maximum reductions sought in } \\
\text { discrete consumption components } \\
\text { (e.g. food, energy, consumables, } \\
\text { etc.) }\end{array}$ & $\begin{array}{l}\text { Reductions negotiated around } \\
\text { the } \mathrm{SAB} \text { that foster interactions } \\
\text { among consumption domains to } \\
\text { produce synergies and therefore } \\
\text { greater reduction as a result }\end{array}$ \\
\hline $\begin{array}{l}\text { 6. Uniformity vs. discreteness of } \\
\text { solution }\end{array}$ & $\begin{array}{l}\text { A general framework with } \\
\text { homogeneous standards generated } \\
\text { from global dialogue and } \\
\text { determination among elites }\end{array}$ & $\begin{array}{l}\text { A framework emphasizing } \\
\text { flexibility and variation } \\
\text { convergent with John Todd's } \\
\text { adage, "elegance of solution will } \\
\text { be predicated on uniqueness of } \\
\text { place" }\end{array}$ \\
\hline
\end{tabular}

critical comment, we are not subscribing to the belief that OPL can-or should be attempted to be-achieved at the neighborhood level.)

Moreover, the largely top-down process of determining these cutbacks leads Moore to outline a series of changes in planning policy and urban management by city administration (the City as actor/enabler) to support or ratify a one-planet lifestyle (Moore 2013: 214-217). Here, Moore identifies eighteen actions to align Vancouverites' ecological footprint with OPL. Only two remain within the agenda of the City of Vancouver's green action plan. Of the remaining sixteen action-items, seven reside outside the scope and authority of the City; three of the remaining nine stand beyond the scope of the City's jurisdiction (though city offices and agencies would have an important part to play in enabling implementation); and of the last six, the City has at best 
limited jurisdiction. This assessment of administrative authority and power is quite sobering and raises an issue that both the Moore/Rees and Yanarella/ Levine strategies must bear in mind.

Given the technocratic impulse detected in the Moore and Rees approach and the weak participatory thrust of its implementation, they can be rightfully chastised for completely marginalizing the critical importance of civil society and citizen capacity-building in bringing to fruition their fair Earthshare vision. In the SUCCESS project in nine villages in China and in the Westbahnhof project in Vienna, the CSC-Oikodrom research teams found that galvanizing the resources of civil society was a key component of these sustainable village/ sustainable implantation projects (Yanarella and Levine 2011: 183-206 and 165-181, respectively). Likewise, in the Southeast False Creek case, citizen action groups inhabiting civil society were crucial to the project moving forward and integrating a significant measure of strong sustainability into the sustainability-oriented community (Yanarella and Lancaster 2016: 211-233).

Any strategy of EF reduction intent on getting from here (many-planet living) to there (one-planet living) must acknowledge the scalar trap in which one- or two-scale approaches can become ensnared. Brown and Purcell (2005: 608) define the "local" or "scalar trap" as the tendency of social analysts to treat policy issues as essentially a locally scaled problem whose dynamics are exhausted within a single level of analysis and thus to explain them predominantly within that scale or "level." As Yanarella and Lancaster (2016) show in numerous case studies of urban sustainability campaigns in North America and as highlighted in a mini-case study (Levine and Yanarella 2016), the politics of scale is often implicated in sustainable city/eco-city initiatives and a multi-scalar approach would seem to be useful or perhaps essential in negotiating the Charybdis and Scylla of getting from here to there. While the implications of the scalar trap do not vitiate the strategy of negotiating means of aligning ecological footprint with EFS/SAB parameters, avoiding the scalar trap does have significant ramifications for developing a strategy for politically coordinating the multi-scaled/multi-jurisdictional elements and players involved in the actually existing and idiosyncratic game of power and politics, in which academic researchers are only one type of player and often not the most influential or versatile.

The rejection of the city-region as the place to embed strong sustainability puts into relief and raises important questions about the latest move in Moore's (and perhaps Rees') research program to establish International Ecocity Framework and Standards (IEFS). This framework was an important part of the 2015 Ecocity World Summit. Based upon an IEFS brochure written by Jennie Moore and several collaborators, this initiative "seeks to provide an innovative vision for an ecologically-restorative human civilization as well as a practical methodology for assessing and guiding progress toward the goal" (Moore et 
al. 2013, rev. 2014). How does this framework and set of standards connect to the city scale? Given Moore and Rees' commitment to a scale-free strategy for EF reduction, is the emphasis on the delimited city scale not contradictory - or is it merely opportunistic? Do this framework and standards address any of the shortcomings we have observed in their Fair Earthshare approach - especially the agricultural/regional component we regard as integral to a holistic approach? Will this framework and standards be flexible and open enough to take into account the idiosyncrasies of cities across the world? Or will the IEFS become a Procrustean bed and risk imposing stultifying uniformity rather than subtle guidelines and direction for actually existing cities aiming to move toward strong urban sustainability? How will the global network advancing this new initiative function if it is to be a handmaiden of urban sustainability and not fall into the danger of becoming a legitimizer of best practices with covert biases stemming from differential power among representatives of its national members? (See Levine and Yanarella 2016 for the hazards of international bodies and award-granting national organizations taking on this role.) The materials emanating from this latest globally-networked initiative are few and so far we look through a glass darkly for details. More information will assist in answering the preceding questions.

\section{IN/CONCLUSION, NEW BEGINNING}

Written over ninety years ago from a filthy Italian prison during the regime of Benito Mussolini, Antonio Gramsci wrote: "the old is dying and the new cannot be born; [and] in this interregnum a great variety of morbid symptoms appear[s]" (1971: 276). For us, this observation captures well the crisis we face and the politically contradictory nature of our times. Precisely at a time when we most need global collaboration and national consensus on the formidable crises and challenges we are confronting, our politics is being taken hostage by forces that seek to widen social inequality, trash science, close our eyes to the enormous dangers galloping toward us, pollute our public sphere with myths, fantasies, and illusions, and drown our democratic institutions and deteriorating elective processes with a tidal wave of corporate money. In the face of the American withdrawal from the Paris Accords, the world community looks to China for global leadership in stemming the climate change threat - and its leader Xi Jinping seems to be seizing this opportunity.

Meanwhile, William Morris reminds us in his under-appreciated classic, A Dream of John Ball, of one of the ironies of politics and collective political struggle, when his fictional medieval protagonist and rebel is moved to say at his hanging, "while I pondered all these things, and how men fight and lose the battle, and the thing that they fought for comes about in spite of their defeat, and when it comes, turns out not to be what they meant, and other men have 
to fight for what they meant under another name" (Morris 1888: 21). For us in this place and at this time, Morris' renegade hero is pointing to how things like green products, practices, and projects today can seem so appealing and marketable at precisely the moment when deeper, stronger, and more engaged embodiments of sustainability are experiencing their greatest resistance and appearing to reach their lowest ebb. As a result, when the sustainability (or is it the green or resilience?) revolution has been won, the pursuit of strong sustainability may have to be fought for again, perhaps by another name.

Today, when global capital is on the move, when technological advances are on the verge of providing powerful new tools for better, more participatory forms of planning and governance, when sustainable city-regions are so compelling, when their construction in the face of incipient climate change and other emerging scarcities is so needful, dangerous forces and alarming circumstances seem to be conspiring to block the fulcrum of strong urban sustainability from moving the world to global sustainability and resolving so many of these downward spiraling crises. But that is no excuse for succumbing to a politics of cynicism and fatalism. Even these dangerous challenges offer different pathways to recovering the dream of true and robust sustainability.

An emergent future of mounting ecological scarcities can provide impetus to embrace a green economy organized around sustainability-oriented products, sustainability practices, and sustainability-driven institutions. National quests for the "new normal" fashioned by the limitations imposed by destructive capitalism upon nature's bounties and nature's services may lead to a serious turn in national economies and the global political economy away from transnational corporate-led globalization and toward the relocalization of economies disciplined by the new and daunting realities of resource scarcities and lifted by the possibilities of the energy bounty of our sun. Who seriously doubts that, in the face of our most formidable challenges stemming from climate change, the world of fast capitalism driven by the consumerist imperative and underwritten by cheap energy will have to give way to a wholesale change in the things that we most value, the lifestyles that our children and grandchildren will live, and the social and economic practices that structure our personal and collective existence? Clearly the leaders in these new ways are China and the Scandinavian countries.

To conclude: answering the opening and lingering question-what is sustainability? - we may say that it is an evolving puzzle of contradiction and contestation, an unending game of political struggle for each new generation, and a journey of hope and possibility for good men and women and an emerging generation seeking a better place, even a practical utopia. 